\title{
Review of Critical Analysis of Frame Building Structure by Wind Force
}

\author{
Sandeep Tembhurkar ${ }^{1}$, Dr.Valsson Varghese ${ }^{2}$ \\ ${ }^{1} M$-Tech student of civil Engg. Department, K.D.K.C.E \\ ${ }^{2}$ Professor and Head of civil Engg. Department, K.D.K.C.E.
}

\begin{abstract}
This paper presents a study of wind loads to decide the design critical parameter of a multistoried building. The significant of this work is to estimate the design loads estimate based on the basic wind speed and other factors of a structure.

In the present study, review of paper in used is the critical analysis of frame structure is made, to valued in study a multistoried building is analyzed for wind loads using IS 875 code. The wind loads are estimated based on the design wind speed of that zone.The wind loads so obtained on the building have been compared for different building. Finally it is found the wind loads are more critical in bending moment, shear force and displacement.
\end{abstract}

Key words: Critical analysis, Zone factor, wind loads, earthquake loads, design loads, high rise buildings.

Guoquing huang , Xinzhong chen.[2007]

\section{Literature Review:}

In this research they found that the effect of wind force, along wind displacement, shear force and bending moment at different building elevations of the 50-story building at wind speed $=46.6 \mathrm{~m} / \mathrm{s}$ calculated from the Time History Analysis, along this wind the top displacement is $1.16 \mathrm{~mm}$, top shear force is $3.94 \mathrm{KN}$ and bending moment is $3.94 \mathrm{KN}-\mathrm{m}$.

The wind load effects of 20- and 50-story buildings in three primary directions were analyzed using detailed dynamic pressure data measured in a wind tunnel. The results of this study reconfirmed some of the findings of previous studies using simplified loading models, and presented some new results that helped to better understand and quantify wind induced response of tall buildings.

The GRFs for the along wind top displacement, base shear force and base bending moment are close to each other. However, use of a single ESWL as the mean wind load multiplied by the GRF associated with the building top displacement or base bending moment led to noticeable underestimates of the story forces at upper floor levels.

\section{A.U.Weerasuriyan andM.T.R.Jayasinghe. [1998]}

In this research they analyzed for $183 \mathrm{~m}$ tall building. The governing load observed for load combination of $1.2 \mathrm{DL}+1.2 \mathrm{Q}+1.2 \mathrm{~W}$ and for this combination, bending moment has maximum about $35 \%$ in column and about $48 \%$ for the beams. However, column maximum axial load variation is in the range of $10 \%$. This value is as high as $17 \%$ when wind load is governing as in load combination $1.0 \mathrm{DL}+1.4 \mathrm{~W}$. The bending moment value is higher as 50\% for the column and more than 55\% for beam bending moments for load combination 1.4DL+1.4W.

For the governing load case $1.2 \mathrm{G}+1.2 \mathrm{Q}+1.2 \mathrm{~W}$,all wind loading standards gave almost the same wind load except wind loads for the Australian standards in zone 1. Australian Standards gave higher wind loads in zone 1 because of they used higher terrain-height multiplier and an importance factor for cyclonic region, zone 1. The use of higher terrain height multiplier in cyclonic region can be justified because of higher risk level are required to design buildings in cyclonic regions. However, the use of importance factor 1.1 may leads to more conservative wind load design and thus it is recommended not to use it with higher terrain height multiplier. Euro code also derived higher wind loads due to higher pressure coefficient values used by the code.

\section{Bogusz Bienkiewicz1, Munehito Endo1, Joseph a. Main2,and william p. Fritz.[2001]}

In this research they analysis paper of two building for wind force, having the different dimensions that wind induced internal force (bending moment) in the frame geometry. That force produced the $90 \%$ peak bending moment in the two frames. In a first building bending moment comes $31.2 \mathrm{KNm}$ at the height of $6.1 \mathrm{~m}$ and in second building it was $32.4 \mathrm{KNm}$ at the height of $9.45 \mathrm{~m}$. which is maximum in both structure.

Results of an ongoing inter-laboratory comparative study of approach flow, wind pressures on low buildings and internal wind-induced loading are presented. The largest variability in the laboratory wind pressures and in the associated (computed) wind-induced internal loading (bending moment) in structural frames 
of generic low buildings was found for suburban wind exposure. This variability was primarily attributed to differences in the approach flows employed in physical modeling of wind pressures on tested buildings, carried out by the participating laboratories. The variability in the approach flows resulted in a large measure from the differences in the along-wind turbulence intensity implied by different empirical models, defining the target wind exposures and used by the laboratories. A follow-up comparative inter-laboratory study is planned to address a number of issues identified in the ongoing efforts.

\section{Dennis C.K., Poon P.E.[2001]}

In this analysis paper, they have analysised the $190.85 \mathrm{~m}$ height tower for wind and earthquake forces and take the wind displacement result on the $48^{\text {th }}$ and $35^{\text {th }}$ floor which was the maximum, on that floor the deflection is $95.6 \mathrm{~mm}$ in $\mathrm{X}$ direction of building.

\section{M.D.Wijeratne And M.T.R.Jayasinghe.}

In this analysis they applied the wind force $33 \mathrm{~m} / \mathrm{s}$ and $38 \mathrm{~m} / \mathrm{s}$ on building structure in Shri-lanka. The structure consist of 40, 50 and 60 storey having $160 \mathrm{~m} 200 \mathrm{~m}$ and $240 \mathrm{~m}$ height respectively range with height breath ratio. They found the maximum deflection for 40 storey $-239 \mathrm{~mm}$, 50storey $-340 \mathrm{~mm}$ and for 60 storey $478 \mathrm{~mm}$. they observed that deflection was too large so they applied some shear walls and tried to reduced the maximum deflection $96 \mathrm{~mm}$ to $212 \mathrm{~mm}$.

Design of high rise building with unusually low design wind speeds will allow the designers to select less rigid structural forms which may have unacceptably high acceleration even at lower wind speeds. for high rise building for the post disaster wind speed given for zone 3.The use of a higher wind speed will automatically constrain the structural designer to select sufficiently stiff structure forms with low drift indicates.

\section{Bianca R. Parv and Monica P. Nicoreac.[2012]}

In this analysis of structure they have analyzed 25floor building having the height of $87.5 \mathrm{~m}$ for the horizontal uniformly distributed load, from wind, acting on both side direction is $28 \mathrm{kn} / \mathrm{m}$ and $24 \mathrm{kn} / \mathrm{m}$ by equivalent column method and FEM method. they found max. Deformation at Umax is $1.3 \mathrm{cmfor}$ ECM and 1.2 for FEM and $V \max$ is $12.05 \mathrm{~cm}$ and $10.70 \mathrm{~cm}$ for ECM and FEM respectively. They obtained the results for max shear force for ECM is $1225 \mathrm{kn}$ in $\mathrm{X}$ direction and $1050 \mathrm{knin}$ y direction and for FEM is $1232.5 \mathrm{kn}$ in $\mathrm{X}$ direction and in $\mathrm{Y}$ direction is $1050 \mathrm{kn}$. They found the maximum bending moment for ECM is $53594 \mathrm{kn}-\mathrm{m}$ in $\mathrm{X}$ dirct. And $45938 \mathrm{kn}-\mathrm{m}$ in Ydirection and for FEM is $53592.75 \mathrm{kn}-\mathrm{m}$ in $\mathrm{X}$ direction and $45935 \mathrm{kn}-\mathrm{m}$ in $\mathrm{y}$ direction.

The focus of this article is to present an approximate method of calculation based on the equivalent column theory. This approximate method of calculation may be successfully applied in the case of tall buildings. Knowing the geometrical and stiffness characteristics of the structure, applying the equivalent column theory may determined: the displacements in both directions, the rotation of the structure, critical load, shear forces, bending moments for each resisting element and the torsional moment of the structure. The results obtained using the approximate calculation method will be compared with the results obtained using an exact calculation based on F.E.M.

Analyzing the results obtained for lateral displacements can noticed that the displacements in both directions are smaller than the maximum displacement allowed by codes $H / 500=17.50 \mathrm{~cm}$. The values of lateral displacements, fundamental frequency, shear forces and bending moments, calculated using the exact method and the approximate method of calculation are very closed, in some cases the values are identical. Thus, it can be said that the two calculation methods have been applied correctly. The same structure have been calculated for 35 floors with a total height of $122,50 \mathrm{~m}$ and an horizontal load qx=27 kN/m2 and qy=31.5 kN/m2

\section{Swati D.Ambadkar, Vipul S. Bawner[2012]}

In this analysis study they have analyzed $40 \mathrm{~m}$ multi storied building at $50 \mathrm{~m} / \mathrm{s}$ wind force for I Category of terrain in India. They found the maximum values of shear forcet is $65.322 \mathrm{kn}$. bending moment is $97.823 \mathrm{kn}$ $\mathrm{m}$ and deformation is $105.147 \mathrm{~mm}$.

As the wind speed increases My, Mz values also increases according to the category, opening as compare to $\mathrm{Mz}$ values My values increased more rapidly. As the wind speed increases Fy, Fz values also increases according to the category, opening as compare to Fz values Fy values increased more rapidly. Displacement increases as the wind speed increases for various types of opening, category.

\section{Daryl W. Boggs, Noriaki Hosoya, and Leighton Cochran[2000]}

In this study they have analyzed 28 storey building. They have applied the wind force at various rotation of building ( 25 to 360 degree rotation) for finding the torsional force in bulding and they have found maximum torque $(\mathrm{Mz}$ direction) at initial stage of applying of load was $335 \mathrm{k}-\mathrm{ft}$ Torsional wind loading on 
buildings is not as well understood as lateral or over-turning loads, and is not as amenable to analytical treatment. Because of this, many designers - and indeed most codes of practice-ignore this aspect of the load, and simply apply the lateral load at the geometric or elastic center of the structure. Wind-tunnel tests on model buildings have revealed that torsional loads usually exist, and span a great range of significance. Several causes of the torsion can be identified, and this categorization aids the designer in providing methods to either reduce or manage the loading. This paper identifies some common sources of torsional loading in terms of building shape, interfering effects of nearby buildings, and dynamic characteristics of the structural frame. In addition, it is shown that torsional loading is routinely larger than that provided for in most standards.

This normalized eccentricity gives a common and intuitive indication of the additive effect of torsion on the total building shear, at a given wind direction. Often the maximum eccentricity does not occur at the same wind direction as the maximum shear, as demonstrated by the graphs in Figure 1. In general the governing design case is not obvious and will depend on the torsion-resistance properties of the frame. For example, if torsion is resisted by shear walls placed near the ends of the building then a given torque may increase the shear stresses only slightly, and the wind direction of maximum overall building shear may well represent the design case. However, if the shear walls are concentrated near the core then the same torque will produce a much greater shear stress, and the design condition is more likely to occur at the direction of maximum eccentricity.

Torsion arises from a number of causes: building shape, interference effects, and dynamic response. Engineers have slight influence on the first, none on the second, but much on third. Torsion cannot be eliminated but can possibly be minimized, or at least designed for if recognized. Wind tunnel studies have been the only way to identify torsion, but they also provide help in minimizing it or designing for it.

To Evaluate The Critical Value, G+19, G+24 And G+29 Model Is Considered And Analyzed By Wind Staad Pro.

Wind Load Analysis

Data Selection For Wind Load Intensities Form Is875 (Part 3) -1987

\begin{tabular}{|l|l|l|}
\multicolumn{2}{c}{ 1. Wind force } & {$[1]^{*}$} \\
\hline i) & Basic wind speed zone & Zone III \\
\hline ii) & Location site & $\begin{array}{l}\text { Nagpur City, } \\
\text { Maharashtra }\end{array}$ \\
\hline iii) & Basic wind speed & $44 \mathrm{~m} / \mathrm{s}$ \\
\hline
\end{tabular}

2.Terrain category ${ }^{[2]}$

\begin{tabular}{|l|l|l|}
\hline i) & Category 2 & Class C \\
\hline \multicolumn{3}{|c|}{ 3. Topography } \\
\multicolumn{3}{|c|}{]$^{*}$} \\
\hline i) & Topography factor & 1 \\
\hline
\end{tabular}

II. Design Wind Speed (Vz)

Where ; $\mathrm{Vz}=\mathrm{Vb} \times \mathrm{k} 1 \mathrm{x}$ k2 $\mathrm{x}$ k3

$\mathbf{V z}=$ Design Wind Speed At Any Height ' $Z$ ' In M/S.

$\mathbf{V b}=$ Basic Wind Speed (clause 5.2, appendix a)

k1 = Probability Factor (Risk Coefficient ,clause 5.3.1)

k2 = Terrain, Height And Structure Size factor(clause 5.3.2) and

k3 = Topography Factor (clause 5.3.3) (* clause taken from IS: 875 (part 3)-1987)

\section{Design Wind Pressure (Pz):}

$$
\mathrm{pz}=0.6(\mathrm{Vz})^{2}
$$

where,

$\mathbf{p z}=$ design wind pressure in $\mathrm{N} / \mathrm{m}^{2}$ at height ' $\mathrm{Z}$ ' and

$\mathbf{V z}=$ design wind velocity in $\mathrm{m} / \mathrm{s}$ at height ' $\mathrm{Z}$ '.

3)-1987)

This calculated Design Wind Speed and Wind Pressure for the $10^{\text {th }}$ floor will same for Model 1 and 2 but these loads varies from $15^{\text {th }}$ floor up to $20^{\text {th }}$ floor storey of Model 1and up to $25^{\text {th }}$ storey of Model 2.

\section{Wind Load On Individual Members:}


$\mathbf{F}=(\mathbf{C p e}-\mathbf{C p l}) \mathbf{A} \cdot \mathbf{p z}$

Where :

Cpe - external pressure coefficients

$\mathrm{Cpl}$ - internal pressure coefficient

A - surface area of structure elements or cladding unit.

wind pressure.*(clause 6.2.1, Pg.No -13, IS: 875 (part 3)-1987)

$\mathrm{pz}-$ Design

- External pressure coefficient : Cpe

The external pressure will calculate on exterior walls. this pressure find as per clause 6.2.2 -6.2.2.1 and Table 4, Pg.no.13, 14\& 15 of IS: 875 (part 3)-1987.

- Internal pressure coefficient : $\mathbf{C p l}$

The internal pressure will calculate on exterior walls. this pressure find as per clause 6.2.3 -6.2.3.1, Pg.no.27 of IS: 875 (part 3)-1987.

\section{Building Parameters :}

1. Dimensions of building : $20 \mathrm{~m} \mathrm{X16} \mathrm{m.}$

2. Height of building $: 70 \mathrm{~m}$ and $87.5 \mathrm{~m}$ of 20 storey and 25 storey respectively( $3.5 \mathrm{~m}$ of each floor)

3. Depth of foundation $: 2.5 \mathrm{~m}$

4. Wall thickness $: 0.23 \mathrm{~m}$

\section{Load Calculation :}

Wind Data:

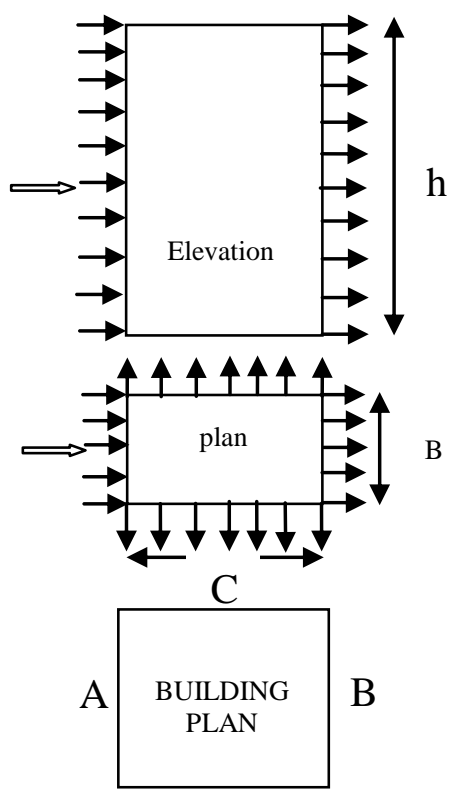

$\mathrm{D}$

Fig.no.1. Pressure distribution on the external surface of a building.

1.Wind Zone : Zone III ( $\mathrm{Vb}=44 \mathrm{~m} / \mathrm{s})$ (refer Appendix A Clause5.2)

2.Terrain Category : Terrain Category 2. Class C. (refer Table no 2 Clause5.3.2)

\section{Design Factors:}

Risk Coefficient Factor $\mathrm{K}_{1}=1.00$

Terrain \& Height Factors $\mathrm{K}_{2}=0.93$ for $10 \mathrm{~m}$ And other value find by interpolating the height and category value.

\begin{tabular}{|c|c|c|}
\hline Wind angle & $\mathbf{0}^{\mathbf{0}}$ & $\mathbf{9 0}^{\mathbf{0}}$ \\
\hline Wall A & +0.7 & -0.5 \\
\hline Wall B & -0.4 & -0.5 \\
\hline Wall C & -0.7 & +0.8 \\
\hline Wall D & -0.7 & -0.1 \\
\hline
\end{tabular}

\begin{tabular}{|l|l|}
\hline & $\mathrm{K} 2$ \\
\hline $10 \mathrm{~m}$ & 0.930 \\
\hline 10.50 & $\mathbf{X}=\mathbf{0 . 9 3 4}$ \\
\hline 15 & 0.97 \\
\hline
\end{tabular}

$=0.930+\{(0.97-0.93) / 15-10)\} \times(10.50-10)$ 
$=\mathbf{0 . 9 3 4}$

Topography Factor $\mathrm{K}_{3}=1.00$

Tributary Area of short wall

$=16.92 \times 3.5=59.22 \mathrm{~m}^{2}$

Tributary Area of long wall

$=21.15 \times 3.5=74.025 \mathrm{~m}^{2}$

Design Wind Speed (Vz) :

Wind Load Calculation:

$\mathbf{F}=(\mathbf{C p e}-\mathbf{C p i}) \mathbf{A} \cdot \mathbf{p z}$

(Refer clause no-6.2.1)

Internal pressure $\mathrm{Cpi}= \pm 0.5$ for medium opening between 5 to 20 percentage.)

External pressure $\mathrm{Cpe}=$ on roof - using table 4 with roof angle $0^{\circ}$ without local coefficient.

Design Pressure For Wall :

$\mathrm{h} / \mathrm{w}=\mathbf{7 0} / \mathbf{1 6 . 9 2}=4.139$, and

$\mathrm{l} / \mathrm{w}=\mathbf{2 1 . 1 5} / \mathbf{1 6 . 9 2}=\mathbf{1 . 2 5}$

External pressure coefficient Cpe for wall

(Refer table 4 clause 6.2.2)

External pressure coefficient on the short wall and long wall

Cpnet for wall A and B

Cpnet for wall C and D

$=+0.7-(-0.5)=1.2($ A wall $)$

$=-0.7-(-0.5)=-0.2(\mathrm{D}$ wall $)$

$=-0.4-(+0.5)=-0.9(\mathrm{~B}$ wall $)$

$=-0.7-(+0.5)=-1.2(\mathrm{C}$ wall $)$

$=+0.5-(-0.5)=1.0($ A wall $)$

$=-0.1-(-0.5)=-0.6(\mathrm{D}$ wall $)$

$=-0.5-(+0.5)=-1.0(\mathrm{~B}$ wall $)$

$=-0.8-(+0.5)=-1.3(\mathrm{C}$ wall $)$

Wind pressure for Short wall

IV. Design Pressure On Wall :

$\mathrm{Pz} \times$ external pressure

$\mathrm{F}=1.00 \times 1.2=\mathbf{1 . 2} \mathrm{KN} / \mathbf{m}^{2}$ pressure $\left(\right.$ at $\left.0^{0}\right)$

$\mathrm{F}=1.00 \times 0.9=0.9 \mathrm{KN} / \mathrm{m}^{2}$ pressure $\left(\right.$ at $\mathbf{0}^{\mathbf{0}}$ )

Wind pressure for long wall

$\mathrm{F}=1.00 \times 1.2=\mathbf{1 . 2} \mathrm{KN} / \mathbf{m}^{2}$ pressure (at $\mathbf{0}^{0}$ )

$\mathrm{F}=1.00 \times 1.2=0.9 \mathrm{KN} / \mathbf{m}^{2}$ pressure $\left(\right.$ at $\left.\mathbf{0}^{0}\right)$

Wind pressure for short wall

$\mathrm{F}=1.00 \times 1.00=\mathbf{1 . 0 0} \mathrm{KN} / \mathrm{m}^{2}$ pressure $\left(\right.$ at $90^{0}$ )

$\mathrm{F}=1.00 \times 1.00=1.00 \mathrm{KN} / \mathrm{m}^{2}$ pressure $\left(\right.$ at $\left.90^{\circ}\right)$

Wind pressure for long wall

$\mathrm{F}=1.00 \times 1.3=1.3 \mathrm{KN} / \mathrm{m}^{2}$ pressure $\left(\right.$ at $\left.90^{0}\right)$ 
$\mathrm{F}=1.00 \times 0.6=0.6 \mathrm{KN} / \mathrm{m}^{2}$ pressure $\left(\right.$ at $\left.^{90}{ }^{\circ}\right)$

\begin{tabular}{|c|c|c|c|c|c|c|c|c|c|c|}
\hline \multirow{2}{*}{ Height $(\mathrm{m})$} & $\mathrm{k}_{2}$ & $\begin{array}{c}\mathrm{P}_{\mathrm{z}} \\
\left(\mathrm{kN} / \mathrm{m}^{2}\right)\end{array}$ & \multicolumn{3}{|c|}{$\begin{array}{c}\text { Wind pressure Along 0 degree } \\
\left(\mathrm{kN} / \mathrm{m}^{2}\right)\end{array}$} & \multicolumn{4}{c|}{$\begin{array}{c}\text { Wind pressure Along } \\
\left(\mathrm{kN} / \mathrm{m}^{2}\right)\end{array}$} \\
\hline & & & $\mathrm{A}$ & $\mathrm{B}$ & $\mathrm{C}$ & $\mathrm{D}$ & $\mathrm{A}$ & $\mathrm{B}$ & $\mathrm{C}$ & $\mathrm{D}$ \\
\hline 3.5 & 0.930 & 1.00 & 1.20 & 0.90 & 1.20 & 1.20 & 1.00 & 1.00 & 1.30 & 0.60 \\
\hline 7.0 & 0.930 & 1.00 & 1.20 & 0.90 & 1.20 & 1.20 & 1.00 & 1.00 & 1.30 & 0.60 \\
\hline 10.5 & 0.934 & 1.01 & 1.21 & 0.91 & 1.21 & 1.21 & 1.01 & 1.01 & 1.31 & 0.61 \\
\hline 14.0 & 0.962 & 1.07 & 1.28 & 0.96 & 1.28 & 1.28 & 1.07 & 1.07 & 1.39 & 0.64 \\
\hline 17.5 & 0.985 & 1.13 & 1.36 & 1.02 & 1.36 & 1.36 & 1.13 & 1.13 & 1.47 & 0.68 \\
\hline 21.0 & 1.004 & 1.17 & 1.40 & 1.05 & 1.40 & 1.40 & 1.17 & 1.17 & 1.52 & 0.70 \\
\hline 24.5 & 1.018 & 1.20 & 1.44 & 1.08 & 1.44 & 1.44 & 1.20 & 1.20 & 1.56 & 0.72 \\
\hline 28.0 & 1.032 & 1.24 & 1.49 & 1.12 & 1.49 & 1.49 & 1.24 & 1.24 & 1.61 & 0.74 \\
\hline 31.5 & 1.045 & 1.27 & 1.52 & 1.14 & 1.52 & 1.52 & 1.27 & 1.27 & 1.65 & 0.76 \\
\hline 35.0 & 1.055 & 1.29 & 1.55 & 1.16 & 1.55 & 1.55 & 1.29 & 1.29 & 1.68 & 0.77 \\
\hline 38.5 & 1.066 & 1.32 & 1.58 & 1.19 & 1.58 & 1.58 & 1.32 & 1.32 & 1.72 & 0.79 \\
\hline 42.0 & 1.076 & 1.34 & 1.61 & 1.21 & 1.61 & 1.61 & 1.34 & 1.34 & 1.74 & 0.80 \\
\hline 45.5 & 1.087 & 1.37 & 1.64 & 1.23 & 1.64 & 1.64 & 1.37 & 1.37 & 1.78 & 0.82 \\
\hline 49.0 & 1.097 & 1.40 & 1.68 & 1.26 & 1.68 & 1.68 & 1.40 & 1.40 & 1.82 & 0.84 \\
\hline 52.5 & 1.104 & 1.41 & 1.69 & 1.27 & 1.69 & 1.69 & 1.41 & 1.41 & 1.83 & 0.85 \\
\hline 56.0 & 1.108 & 1.43 & 1.72 & 1.29 & 1.72 & 1.72 & 1.43 & 1.43 & 1.86 & 0.86 \\
\hline 59.5 & 1.113 & 1.44 & 1.73 & 1.30 & 1.73 & 1.73 & 1.44 & 1.44 & 1.87 & 0.86 \\
\hline 63.0 & 1.118 & 1.45 & 1.74 & 1.31 & 1.74 & 1.74 & 1.45 & 1.45 & 1.89 & 0.87 \\
\hline 66.5 & 1.123 & 1.47 & 1.76 & 1.32 & 1.76 & 1.76 & 1.47 & 1.47 & 1.91 & 0.88 \\
\hline 70.0 & 1.128 & 1.48 & 1.78 & 1.33 & 1.78 & 1.78 & 1.48 & 1.48 & 1.92 & 0.89 \\
\hline 73.5 & 1.133 & 1.49 & 1.79 & 1.34 & 1.79 & 1.79 & 1.49 & 1.49 & 1.94 & 0.89 \\
\hline 77.0 & 1.138 & 1.50 & 1.80 & 1.35 & 1.80 & 1.80 & 1.50 & 1.50 & 1.95 & 0.90 \\
\hline 80.5 & 1.143 & 1.52 & 1.82 & 1.37 & 1.82 & 1.82 & 1.52 & 1.52 & 1.98 & 0.91 \\
\hline 84.0 & 1.148 & 1.53 & 1.84 & 1.38 & 1.84 & 1.84 & 1.53 & 1.53 & 1.99 & 0.92 \\
\hline 87.5 & 1.152 & 1.54 & 1.85 & 1.39 & 1.85 & 1.85 & 1.54 & 1.54 & 2.00 & 0.92 \\
\hline
\end{tabular}

Wind force for short wall

$\mathrm{F}=1.75 \times 1.2 \times 16.92=35.53 \mathrm{KNpressure}\left(\right.$ at $\left.^{\mathbf{0}}\right)$

$\mathrm{F}=1.75 \times 0.9 \times 16.92=\mathbf{2 6 . 6 5 K N p r e s s u r e ~}\left(\right.$ at $\left.^{\mathbf{0}}\right)$

Wind force for long wall

$\mathrm{F}=1.75 \times 1.2 \times 21.15=44.42 \mathrm{KNpressure}\left(\right.$ at $\left.0^{0}\right)$

Table 1: Wind pressures on structure

$\mathrm{F}=1.75 \times 1.2 \times 21.15=\mathbf{4 4 . 4 2} \mathrm{KNpressure}\left(\right.$ at $\left.^{\mathbf{0}}\right)$

Wind force for short wall

$\mathrm{F}=1.75 \times 1.0 \times 16.92=35.53 \mathrm{KNpressur}\left(\right.$ at $^{\mathbf{9}} \mathbf{9 0}^{\circ}$ )

$\mathrm{F}=1.75 \times 1.0 \times 16.92=26.65 \mathrm{KNpressure}\left(\mathbf{a t 9 0}^{\circ}\right)$

Wind force for long wall

$\mathrm{F}=1.75 \times 1.3 \times 21.15=44.42 \mathrm{KNpressure}\left(\operatorname{at90}^{0}\right)$

Table 2: Wind forces on structure

\begin{tabular}{|c|c|c|c|c|c|c|c|c|}
\hline \multirow{2}{*}{$\begin{array}{l}\text { Storey } \\
\text { level }\end{array}$} & \multicolumn{3}{|c|}{ Force } & \multicolumn{1}{|c|}{ Along 0 degree $(\mathrm{kN})$} & \multicolumn{3}{|c|}{ Force Along 90 degree $(\mathrm{kN})$} \\
\cline { 2 - 9 } & $\mathrm{A}$ & $\mathrm{B}$ & $\mathrm{C}$ & $\mathrm{D}$ & $\mathrm{A}$ & $\mathrm{B}$ & $\mathrm{C}$ & $\mathrm{D}$ \\
\hline 1 & 35.53 & 26.65 & 44.42 & 44.415 & 29.61 & 29.61 & 48.12 & 22.20 \\
\hline 2 & 71.06 & 53.30 & 88.83 & 88.83 & 59.22 & 59.22 & 96.23 & 44.42 \\
\hline 3 & 71.77 & 53.83 & 89.72 & 89.72 & 59.81 & 59.81 & 97.19 & 44.86 \\
\hline 4 & 76.04 & 57.03 & 95.05 & 95.05 & 63.37 & 63.37 & 102.97 & 47.52 \\
\hline 5 & 80.30 & 60.23 & 100.38 & 100.38 & 66.92 & 66.92 & 108.74 & 50.19 \\
\hline 6 & 83.14 & 62.36 & 103.93 & 103.93 & 69.29 & 69.29 & 112.59 & 51.97 \\
\hline 7 & 85.28 & 63.96 & 106.60 & 106.60 & 71.06 & 71.06 & 115.48 & 53.30 \\
\hline 8 & 88.12 & 66.09 & 110.15 & 110.15 & 73.43 & 73.43 & 119.33 & 55.07 \\
\hline 9 & 90.25 & 67.69 & 112.81 & 112.81 & 75.21 & 75.21 & 122.22 & 56.41 \\
\hline 10 & 91.67 & 68.75 & 114.59 & 114.59 & 76.39 & 76.39 & 124.14 & 57.30 \\
\hline 11 & 93.80 & 70.35 & 117.26 & 117.26 & 78.17 & 78.17 & 127.03 & 58.63 \\
\hline 12 & 95.23 & 71.42 & 119.03 & 119.03 & 79.35 & 79.35 & 128.95 & 59.52 \\
\hline 13 & 97.36 & 73.02 & 121.70 & 121.70 & 81.13 & 81.13 & 131.84 & 60.85 \\
\hline 14 & 99.49 & 74.62 & 124.36 & 124.36 & 82.91 & 82.91 & 134.73 & 62.18 \\
\hline 15 & 100.20 & 75.15 & 125.25 & 125.25 & 83.50 & 83.50 & 135.69 & 62.63 \\
\hline 16 & 101.62 & 76.22 & 127.03 & 127.03 & 84.68 & 84.68 & 137.61 & 63.51 \\
\hline 17 & 102.33 & 76.75 & 127.92 & 127.92 & 85.28 & 85.28 & 138.57 & 63.96 \\
\hline 18 & 103.04 & 77.28 & 128.80 & 128.80 & 85.87 & 85.87 & 139.54 & 64.40 \\
\hline
\end{tabular}




\begin{tabular}{|c|c|c|c|c|c|c|c|c|}
\hline 19 & 104.46 & 78.35 & 130.58 & 130.58 & 87.05 & 87.05 & 141.46 & 65.29 \\
\hline 20 & 105.17 & 78.88 & 131.47 & 131.47 & 87.65 & 87.65 & 142.42 & 65.73 \\
\hline 21 & 105.89 & 79.41 & 132.36 & 132.36 & 88.24 & 88.24 & 143.39 & 66.18 \\
\hline 22 & 106.60 & 79.95 & 133.25 & 133.25 & 88.83 & 88.83 & 144.35 & 66.62 \\
\hline 23 & 108.02 & 81.01 & 135.02 & 135.02 & 90.01 & 90.01 & 146.27 & 67.51 \\
\hline 24 & 108.73 & 81.55 & 135.91 & 135.91 & 90.61 & 90.61 & 147.24 & 67.95 \\
\hline 25 & 54.72 & 41.04 & 68.40 & 68.40 & 45.60 & 45.60 & 74.10 & 34.20 \\
\hline TOTAL & $\mathbf{2 2 5 9 . 8 4}$ & $\mathbf{1 6 9 4 . 8 8}$ & $\mathbf{2 8 2 4 . 7 9}$ & $\mathbf{2 8 2 4 . 7 9}$ & $\mathbf{1 8 8 3 . 2 0}$ & $\mathbf{1 8 8 3 . 2 0}$ & $\mathbf{3 0 6 0 . 1 9}$ & $\mathbf{1 4 1 2 . 4 0}$ \\
\hline
\end{tabular}

\section{Conclusions}

The wind loads estimated for a twenty storied, twenty five storied and thirty storied RC framed structure. Based on the results obtained the following conclusions are made.

1.from the analysis , it is obtained that critical value of Bending Moment is obtained at 30 storey i.ea at 16.67 $\%$.

- The wind loads increases with height of structure.

- Wind loads are more critical for tall structures.

- Structures should be designed for loads obtained in both directions independently for critical forces of wind.

\section{References:}

[1]. "Wind Load Effects And Equivalent Static Wind Load Of Tall Building Based On Synchronous Pressure Measurements"- By Guoquing Huang , Xinzhong Chen, Wind Science And Engineering Research Center, Department Of Civil And Environmental Engineering,Texas Tech University,Lubbock TX 79409.USA.

[2]. "A Comparative Study Of Wind Standards For Tall Buildings" and "Strategies For Adopting New Trends In Wind Load EvaluationOn Structures"-By A.U.Weerasuriya and M.T.R.Jjayshinghe

[3]. "Comparative Inter-Laboratory Study of Wind Loading on Low Industrial Buildings" By-Bogusz Bienkiewicz1, Munehito Endo1, Joseph A. Main2, and William P. Fritz.

[4]. Wind Engineering and Fluids Laboratory, Department of Civil and Environmental Engineering,Colorado State University, Fort Collins, CO 80523-1320, USA “Analysis and Design of a 47-story Reinforced Concrete Structure -Futian Shangri-La Hotel Tower” ByDennis C.K. Poon P.E., Managing Principal, Thornton Tomasetti.

[5]. "Wind Load For High-rise Building Construction In Shrilanka"by- M.D.Wijeratne And M.T.R.Jayasinghe

[6]. "Global Structural Analysis Of Central Core Supported Tall Building Compared With Fem” By Bianca R. Parv and Monica P. Nicoreac.

[7]. Acta technica napocensis: civil engineering \& architecture vol. 55, no. 3 (2012) journal.

[8]. Behaviour Of Multistoried Building Under The Effect Of Wind Load" By Swati D.Ambadkar, Vipul S. Bawner

[9]. Int. Journal of Applied Sciences and Engineering Research, Vol. 1, Issue 4, 2012 @ 2012 by the authors - Licensee IJASER- Under Creative Commons License 3.0.

[10]. "Sources of torsional wind loading on tall buildings: lessons from the wind tunnel” By - Daryl W. Boggs, Noriaki Hosoya, and Leighton Cochran.

[11]. Advanced Technology In Structural Engineering (proceedings of the 2000 structures congress \& exposition, may 2000, philadelphia), ed. m. elgaaly, sei/asce, 2000 